\title{
An Expert System to Diagnose and Fix Common Car Breakdowns for Industrial Technical Education in Egypt
}

\author{
Mohamed R. Alkotby \\ Department of Computer Teacher \\ Preparation \\ Faculty of Specific Education, \\ Damietta University, Damietta, \\ Egypt
}

\author{
Elsaeed Elsaeed Mohamed \\ Abd Elrazek \\ Department of Computer Teacher \\ Preparation \\ Faculty of Specific Education, \\ Damietta University, Damietta, \\ Egypt
}

\author{
M. Z. Rashad \\ Department of Computer Science \\ Faculty of Computer Science and \\ Information Technology \\ Mansoura University, Mansoura, \\ Egypt
}

\begin{abstract}
As the specialization of cars is one of the specialties found in industrial technical education(ITE) schools and students suffer from many problems highlighted by the results of personal interviews with some experts and specialists in the field of repair and maintenance of cars as well as some teachers of ITE has become clear the need to design the proposed system to help students to improve their knowledge and then skills Which makes them able to join the labor market and keep abreast of the rapid changes and developments in the automotive industry and the complexity of their breakdowns. The proposed system was designed according to the basic stages of expert system; Problem IdentificationConceptualization-Formalization-Application

Implementation- Testing. Knowledge base was put on the cloud computing so that it can be accessed at any time and from any place. The proposed system was applied to a sample of students including 53 students from the specialization of cars divided into two groups; (experimental and standard). The results were analyzed and processed statistically according to the actual application of the proposed system on the research sample. It was found that there were statistically significant differences at the level of (0.05) between the average scores of the students of the standard group (the traditional teaching style) and the experimental group in the knowledge and skills aspects of the experimental group, indicating the effective use of the proposed system and the need for ITE schools.
\end{abstract}

\section{Keywords}

Artificial Intelligence (AI) - Expert System (ES) - Industrial Technical Education (ITE) - Common Cars Breakdowns.

\section{INTRODUCTION}

In order to achieve comprehensive development in all fields in general, and to improve the educational process in particular, this necessitates interest in the development of ITE so that it can provide the society with human expertise capable of meeting the requirements of the labor market.

Traffic accidents are increasing day by day, with about 1.25 million deaths per year due to traffic accidents and 20 million to 50 million other people who are injured due to these accidents, many of which lead to disability[1]. The causes of accidents on roads are the lack of safety of vehicles and their breakdowns during the traffic. The percentage of car accidents resulting from the technical condition of the car amounted to $13.8 \%$ of the total number of car accidents in Egypt [2] due to lack of awareness of the methods of dealing with breakdowns and the lack of regular maintenance of cars.
AI has contributed to the development of many important vital applications, including ES, to assist in learning, decisionmaking, problem solving, etc. The specialization of cars is one of the specialties of ITE schools. And to guide students to the methods and steps of diagnosis and correct fixing of common breakdowns, which improves their skills, and provides them with the time and effort necessary to diagnose and fix common car breakdowns, and to match their skills and requirements of the labor market and contribute to reducing Percentage of road accidents caused by car crashes.

\section{AWARENESS OF PROBLEM}

The researchers aware of the problem is due to the connection of their work to the educational process and the research of the problems associated with it, and the study of one of them at the secondary level in one of the technical schools of industrial education, where he noted the existence of multiple complaints of students in the specialization of cars from their inability to diagnose and fix common car breakdowns. Also conferences' recommendations like the conference of "learn a craft" which is held in Assiut university 2017[3].

The study also conducted a survey study, where $89 \%$ of the sample of the survey confirmed that students have difficulty of diagnosing and fixing car breakdowns Therefore, The current research is concerned with this problem. Hence, the research conducted a number of interviews to identify the most important problems including the diagnosis and fixing of common car breakdowns.

1- Conducting a personal interview with some technical education teachers in order to determine the satisfaction of the teachers of ITE on the level of students and their ability to diagnose common car breakdowns. From this interview it was clear that there was a shortage in training courses because of:

a- The training process in ITE shall be confined to the screwing and the installation of the mechanical parts without identifying the breakdowns and how to deal with them, which is not consistent with the requirements of the labor market.

b- Not allowing students to deal directly with some engines for fear of damaging them.

c- Lack of a technical system that helps students diagnose and fix common car breakdowns.

2- Conducting a personal interview with some specialists in the field of car repair and maintenance. It is clear that:

a - Most workshop owners refuse to employ graduates of ITE because of their low skills in dealing with cars and diagnosis and fixing of breakdowns. 
b - Some of the specialists in the field of car repair said that they have employed some of the graduates of ITE for them, but they caused the destruction of cars.

c - The largest proportion of workshop owners accept the employing of individuals who cannot read and write but have considerable experience in the repair and maintenance of cars more than graduates of ITE, because of the weakness of the skill of graduates of ITE in the diagnosis and fixing of car breakdowns.

d-Workshop owners and managers of car service and repair centers assured the high cost of fault diagnosis devices, their incompatibility with all cars, the constant need for updates and the high costs involved.

\section{RESEARCH PROBLEM:}

There is a shortage in the preparation of students of ITE cars specializing is the low level of skill and knowledge in the diagnosis and fixing of common car breakdowns and this is a problem which the majority of students suffer from, and the current research seeks to find a solution to this problem, In order to provide the students of ITE some of the cognitive and technical aspects of the diagnosis and fixing of common car breakdowns, Based on the above we can summarize the problem of research in the following main question: What are stages of the proposed system to provide the students of ITE some aspects of knowledge and skill to diagnosis and fixing common cars breakdowns?

And also there are sub-questions that the research tries to answer:

a. What are the most important skills that students of ITE must acquire to diagnose and fix common car breakdowns?

b. What is the proposed design of an ES to provide ITE students with some knowledge and skills to diagnose and fix common car breakdowns?

c. What is the effect of applying the proposed system in the field of diagnosis and fixing of common car breakdowns?

\section{RESEARCH HYPOTHESES:}

a- There are statistically significant differences at the level of (0.05) between the average scores of the standard group students (the traditional teaching style) and the experimental group (the teaching style using the proposed ES) in the cognitive aspects in favor of the experimental group.

b- There are statistically significant differences at the level of $(0.05)$ between the average scores of the standard group students (the traditional teaching style) and the experimental group (the teaching style using the proposed ES) in the skill performance and practical efficiency for the experimental group.

\section{SEARCH LIMITS:}

\subsection{Geographic boundaries:}

The search is restricted to Alexandria Governorate

\subsection{Time limits:}

The academic year 2017-2018

\subsection{Human boundaries:}

The current research is limited to a sample of students of the industrial technical secondary school at the "Alexandria Advanced Technical School" and a sample of the students of "Ras Al-Sudha Industrial Secondary School" in Alexandria Governorate

\section{RELATED WORK}

The theoretical framework of this research and associated previous studies will be discussed in the following areas:

\subsection{The first aspect: AI and ES}

Belkasi defined AI as "The science that makes computers think and deal with activities that require human thought, such as decision-making, problem solving, reasoning, and acting." [4] The development of AI technology associated with computer science and its use in education has played an important and effective role in raising the efficiency of the educational process, where it added a variety of modern and effective roles that were not there before.

\subsubsection{Studies that dealt with this aspect}

Amany Mattar (2009),entitled "Suggested Form For Using Expert Systems In Pre-University Education" [5]

- This study aims at providing students with specialized systems to serve the educational process.

- The study concluded that the proposed system for use in pre-university education is clear and easy to apply as a teaching system in pre-university education. It can also be saved and distributed in the field of education in different grades, to evaluate students as an alternative to traditional evaluation methods.

- The current research is consistent with this study in the importance of using and applying ES in the educational process. However, this study focused on the evaluation of students using the proposed system, while the current research aims to help the students to diagnose and fix common car breakdowns.

Yash Jindal (2010), entitled "Approach towards Car Breakdown Diagnosis-An Expert System" [6]

- The aim of the study is to design an ES for diagnosing the breakdown of cars in order to help car owners to identify the breakdown of their cars without need for a mechanic of cars at any time they need.

- The study showed that the cost of the system is lower comparing the human expert in the long term.

- The study also confirmed that if the system is enriched, added and developed it will be suitable for use by car owners to identify the breakdown of their cars and save time, effort and cost.

Saeed Mohammed (2011),entitled "Design of intelligent database system for vehicle fault diagnosis"[7]

- The study aims at designing and implementing a smart database in the field of diagnosing vehicle breakdowns.

- The study has reached the effectiveness of the rule used in the diagnosis of faults where the test of the rule in many cases, and the results of the various cases are consistent with the results of the mechanic of cars.

- The current research consistent with the previous two studies, in designing an ES to help diagnose car breakdowns, adding to them help in handling these 
breakdowns. The system is designed in a flexible system. The system can be updated and developed at any time and from anywhere through internet connection, Thanks to the knowledge base on cloud computing, in an effort to keep up with rapid developments in the automotive industry.

Al-Saidi (2015),entitled "The impact of instructional design expert system in developing the skills of producing electronic courses among graduate students at the faculty of education" [8]

- The aim of the study was to uncover the effect of the design of an educational ES on the development of cognitive and performance aspects related to the skills of producing electronic courses for postgraduate students at the Faculty of Education.

- The study found that there was a statistically significant difference (0.05) among the average scores of the experimental group in the tribal and post application of the cognitive test of the cognitive aspects and the performance aspect note card.

- The results also showed the arrival of the members of the experimental group in the cognitive side, and the performance to the level of perfection.

- The current research is consistent with the study of the impact of the ES on the development of the cognitive and performance aspects of the students, but it is related to a different field of this study, where the current research is related to the diagnosis and fixing of common car breakdowns.

\section{OLANLOYE (2013),entitled "AN EXPERT SYSTEM FOR DIAGNOSING TRACTOR FAILURE AND MALFUNCTION" [9]}

- The aim of this study was to design an ES for diagnosing the breakdown of agricultural tractors.

- The research focused on tractors with four wheels which are powered by gasoline engines.

- The system was tested and found to be promising, according to the researcher.

- The current research is consistent with this study in the design of the ES to assist in diagnosis, but current research uses it to help diagnose and fix common car breakdowns and is applied in ITE.

\subsection{The second aspect: ITE}

The issue of developing education and working to raise its efficiency is one of the most important things that any country seeks to achieve because it plays a great role in achieving the advancement of society and progress and building a conscious personality capable of dealing with the requirements of the age. The ability of nations and their status is measured by their trained manpower to adapt to the latest developments of the age.

Unfortunately, this type of education has been neglected in Egypt over the past years, so that its graduates are seen as second-class graduates. This negligence led to the lack of development of various skills and the lack of human potential.

This type of education was separated from the reality of the market, Where the balance between the supply and demand sides of graduates of industrial secondary schools in the labor market has disappeared [10]. Technical education has become a back door for unemployment through which the graduate receives a certificate but with suspension.

As the specialization of cars is one of the specialties found in the schools of ITE, which suffers from many problems, mainly the difficulty of diagnosing students for car breakdown, the lack of awareness of the methods of correct fixing of these breakdowns and with the exposure of many citizens to fatal road accidents due to a large proportion of cars to crash As a result of the non-specialized and unqualified scientific diagnosis and fixing breakdowns, where the defects of the vehicle in the second place of the causes of accidents on the roads [11].

The current situation requires paying attention to this specialization and working to provide ways to help students to learn effectively so that they can meet the requirements of the labor market, and change the negative perception that was formed over the years of graduates of ITE in general, we have some social problems such as the increase in car accidents, and the high unemployment rates resulting from the lack of compatibility between the potential of graduates of ITE and the requirements of the labor market.

\subsection{1 some Previous Studies Related To Industrial Technical Education Are Presented Below}

Adel Mohammed (2011),entitled "The Effectiveness of a program for developing the skills of cars maintenance course for the industrial secondary schools students in the light of the technological innovations" [12]

- The aim of the study is to develop the skills of car maintenance for students of industrial high school system of three years - specialization of cars - in light of the technological innovations in the labor market.

- Also to verify the effectiveness of the proposed program in providing students with the concepts and skills included in the proposed units in light of the technological innovations in the labor market.

- The study found the effectiveness of the two teaching units proposed within the units of the proposed program in providing students with the concepts and skills included in the units in the light of technological innovations.

- The current study is in line with the study on the development of the knowledge and skills of students in ITE, specializing in cars. However, the current study is related to the practical training part of industrial secondary schools, while this study is related to the content of the maintenance course, and installation without going deeper into how to diagnose faults and propose remedial steps.

Asim Ahmed (2014), entitled "Industrial Secondary Education Outputs and Labor Market Needs in Egypt" [13]

- The study aimed to identify the extent to which the outputs of technical education to the industrial requirements of the labor market and to develop a vision of how to achieve this.

- The study has reached the low level of training and knowledge of graduates of ITE, and its separation from the requirements of the labor market. 
- The current study is in line with the proposed design of the proposed system to help students in automotive technical education schools acquire the knowledge and skills associated with the diagnosis and fixing of common car breakdowns so that there is a correlation between the potential of students and the requirements of the labor market, which in turn reduces unemployment rates. Graduates of technical and industrial education, especially in automotive specialization.

\section{THE PROPOSED SYSTEM}

The research was based on the basic stages of the design of the ES in the field of education that's shown in figure (1).

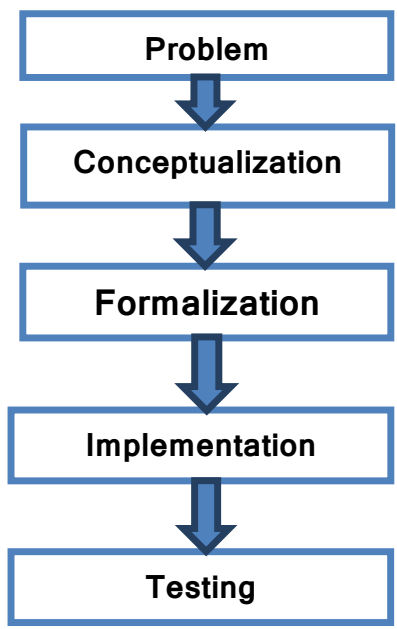

Fig (1) shows the main stages of the proposed system

\subsection{Stage 1: Problem Identification}

The researchers collected as much information as possible from experts in the diagnosis and fixing of car breakdowns, as well as some car repair and repair center managers, some ITE teachers, and auto mechanics.

The researchers needed several meetings with experts. Which are used in the diagnosis of common breakdowns, and have been identified in the breakdowns of startup and brake system breakdowns in addition to the codes of the most common breakdowns associated with the cooling system and others.

\subsection{Stage 2: Conceptualization}

The researchers (who played the role of knowledge engineer) and field experts collaborated to analyze the problem further, review what should be added to the proposed ES, provide detailed explanations, and add any new information related to the area of the ES.

\subsection{Stage 3: Formalization}

The method was chosen to represent the knowledge, and the decision tree style was chosen to suit the nature of the problem associated with the ES. The various breakdowns were formulated in the form of a set of questions and answers. The questions are presented to the user of the system. To propose the steps that fix breakdowns. At this stage, these questions and associated answers have been added to the knowledge base.

\subsection{Stage 4: Application Implementation}

The prototype of the proposed ES was created by programming the concepts that were formulated using the programming languages. This is a minimized model of the
ES, which is designed in such a way that can perform the reasoning processes quickly and construct the rest of the system correctly. At this stage, the researchers noticed that there were some problems of mismatch in the diagnosis of the proposed system in two cases with the diagnosis made by the experts in the field. This required the researchers to make some modifications and improvements to pass from the initial model to the final model.

7.4.1 The proposed system is formed from the following components shown in figure 2:

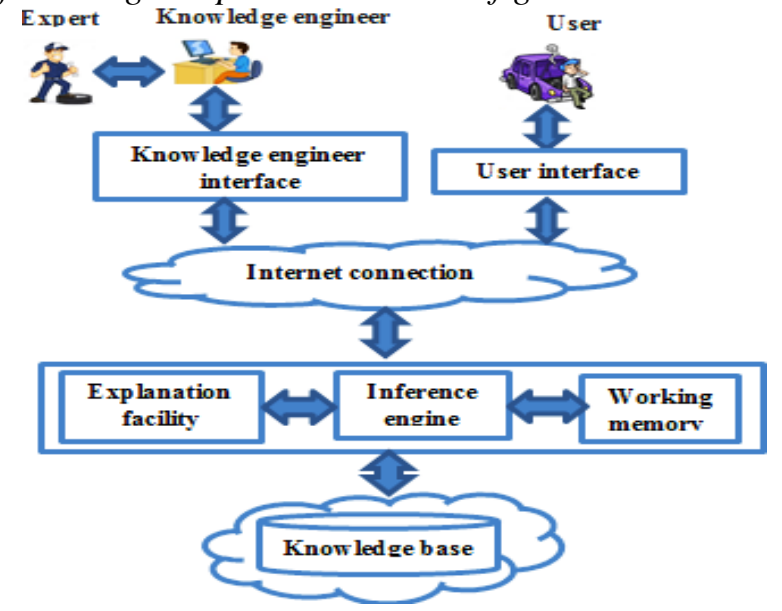

Fig (2) shows the structure of the proposed system

\section{a- User Interface:}

The most important components where the interaction between the user and the ES, and is the final form, which shows the user's ES; therefore, there is a set of criteria that were taken into account when designing that interface is:

- Use terms that are easy to understand by the user.

- The interface is not very complex.

- Consistency of both colors and shapes to attract user attention.

- Interface design in a way that reflects the ES domain. This is shown in figure (3)

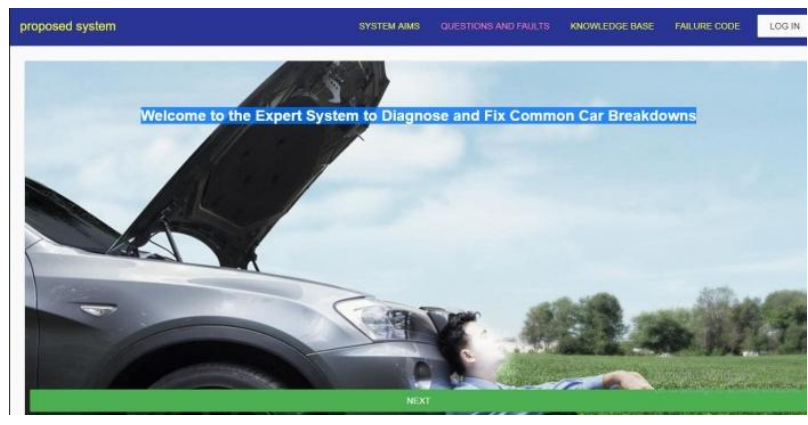

Fig (3) shows the user interface

\section{b- WORKING MEMORY:}

This memory is used to keep a complete record of the final results, which is called short-term memory. It is similar to RAM in the computer. In other words, the working memory contains all the information about the problem, whether the user enters it or the information that the system derives. [14] 
c- Inference Engine:

The Inference Engine is the intellectual mind of the ES. It determines when and how to use the information in the knowledge base, which is a set of programmed actions that lead to the proper solution by linking facts and rules in a way that leads to reasoning. That is; a means of directing the use of information which leads to proper solution.

\section{d- Knowledge base:}

It serves as the core of the system because it contains all the facts related to the problem to be solved, as well as the experience gained and available to experts in this field; ES are sometimes called knowledge-based systems [15] The level of performance of the system is often measured by the size and quality of the knowledge base it contains. Building the knowledge base is one of the most difficult stages in building an ES [16].

\section{e- Explanation Facility:}

The component responsible for explaining how the ES reaches the results in order to achieve a high degree of trust in the decision reached [17]

\subsubsection{The research used the following programs,} languages and tools in the design of the proposed ES

\section{a- Intellij idea}

- Manufacturer: Jet Brains

- Use: It is used in the writing of the codes of the system where the program is characterized by its ability to view the files of the system and show the links between files and each other with its high ability to detect any errors in the writing of the code. [18]

- Features: Easy to deal with the program and the connection between the system files easily and help to detect any errors in the writing of the code.

- Disadvantages: It seems confusing to deal with the program initially, but after identifying and dealing with it, it becomes easy.

b- Adobe Photoshop CS6

- Manufacturer: Adobe

- Use: It is used to make some adjustments to the images used in the proposed system, in order to output them appropriately.

- Advantages: Helps to obtain images with certain specifications and characteristics depending on the needs of the user, and according to the modifications or designs.

- Disadvantages: requires dealing with it to the training in advance, due to the multiplicity of tools.

c- Java script: Is now used in many fields and has been used as an alternative to some AI languages where it leads to the same result, but more easily and simpler [19] and also features that their products can be run on any device and does not require special programs to work Browsers can also be easily converted to applications running on mobile devices (mobile, tablet).

d- Html: A shortcut to the Hypertext Markup Language, which has been used in the interface design and overall layout of the proposed system screens.

e- CSS: A shortcut to the Cascading Style Sheets and was used to add effects and formats to the contents of the proposed system screens. f- Angular js: A framework for Java Script [20]to help use pre-programmed tools and libraries that serve as the infrastructure for the proposed application or system.

g- Node js: A java script runtime based on the java script v8. [21] Is an open source Java operating environment.

h- Firebase Real Time Database: A database available from Google on cloud computing that allows data storage, so that the user can access it anytime and from anywhere over the Internet.

\subsection{Stage 5: Testing}

Where the researchers who played the role of knowledge engineer to test the proposed system in terms of the following:

- The accuracy and efficiency of drafting rules.

- Application accuracy.

This was done by comparing the solutions provided by the proposed ES with the solutions provided by the human expert. The solutions provided by the proposed ES were in line with the solutions provided by experts and specialists in the field of car repair. The proposed system is distinguished with:

- Ability to operate on personal computers and mobile devices (Mobile / Tablet).

- The knowledge base on cloud computing, which facilitates the process of development and modernization at any time and from anywhere and from one device without need to update all the devices that the system works on them.

- Use the proposed system for the Arabic language.

- Support for various cases of defects in illustrations.

- Easy operation and handling of the proposed system.

-The possibility of development and modernization by nonspecialists in programming as the system was designed in a way that allows the addition and deletion of various breakdowns without need to modify the code.

- The simplicity and attractiveness of the interface.

- Ease of use of the proposed system to assist in the diagnosis and fixing of common car breakdowns.

\section{IMPLEMENTATION \\ 8.1 The research sample:}

A total of (53) students of ITE were randomly selected from the Alexandria Advanced Technical School and Ras Al-Sudha Secondary Industrial school in Alexandria Governorate and divided into two groups, experimental groups of (28) students ,and standard group of (25) students.

\subsection{Actual application of the experiment:}

After determining the time and place of conducting the research experiment (school workshop), both the achievement test and the observation card were applied to the students of the standard group, then the test was corrected and the students' grades were collected.

The use of the proposed system was also applied to the students of the experimental group, then the application of the test and the observation card to the students of the experimental group, then the correction of the test and the compilation of the students' grades.

In order to obtain the grades of the students of the two groups (standard and experimental), the statistical process needed to 
obtain the average scores of the students of the two groups were compared to obtain the results of the practical application of the research experiment.

To answer the first question of the research questions:

What are the most important skills that students of industrial technical education must acquire to diagnose and fix common car breakdowns?

The researchers conducted many personal interviews varied in the following categories:

- ITE Teachers.

- Experts and specialists in the diagnosis and fixing of car breakdowns.

- Managers of service centers and car repair.

- Engineers of automotive mechanics.

- Graduates of ITE.

The researchers identified the breakdowns and skills added in the proposed system based on the results of these interviews in addition to the formation of the proposed vision of the system and related to the second question of the research questions.

To answer the second question of the research questions: What is the proposed design of an ES to provide ITE students with some knowledge and skills to diagnose and fix common car breakdowns?

Researchers have followed the basic stages of designing the ES described previously.

The proposed system was designed to help provide students with technical knowledge to diagnose and fix common breakdowns. The researchers took into account the opinions agreed upon by the experts. They also presented the proposed design to the arbitrators to express their opinions through the arbitration form for the proposed system. Their consent after taking notes and making some of the amendments mentioned in the forms.

The proposed system was applied to the research sample at the two schools mentioned in the research limits, after the approval of the arbitrators by the validity of its application.

To answer the third question of the research questions: What is the effect of applying the proposed system in the field of diagnosis and fixing of common car breakdowns?

After the researchers designed the proposed system, it was applied to the sample of the study number (53) students randomly selected and divided into two experimental and standard groups in order to ascertain the effect of the proposed system in helping to provide them with some cognitive and technical aspects to diagnose and cure common car breakdowns to validate Research hypotheses.

In order to test the validity of these hypotheses, a set of tables containing the results of the independent sample t-test between the scores of the students in the standard and experimental groups were prepared in both the achievement test and the observation cards. These tables include the number of students per group, average scores, Significance, standard deviation, as follows
Table 1 shows the value of $T$ test and average scores of the standard and experimental groups in the achievement test

\begin{tabular}{|c|c|c|c|c|c|}
\hline groups & $\begin{array}{l}\text { Numbe } \\
\mathbf{r \quad \text { of }} \\
\text { student } \\
\mathrm{s}\end{array}$ & $\begin{array}{l}\text { averag } \\
\text { e }\end{array}$ & $\begin{array}{l}\text { Standar } \\
\text { d } \\
\text { deviatio } \\
\text { n }\end{array}$ & $\mathbf{T}$ & sig \\
\hline standard & 25 & 6.60 & 1.607 & \multirow{2}{*}{$\begin{array}{l}24 . \\
5\end{array}$} & \multirow{2}{*}{$\begin{array}{l}.00 \\
0\end{array}$} \\
\hline experimenta & 28 & 15.60 & 1.030 & & \\
\hline
\end{tabular}

Table (1) shows the following:

The mean level of significance is less than (0.05), which means rejecting the zero hypothesis and accepting the alternative hypothesis, meaning that there are statistically significant differences at $(0.05)$ between the standard group and the experimental group in the cognitive aspects And for the experimental group, since the average score is (15.60), which is greater than the average score of the standard group (6.60), and the value of $\mathrm{T}$ (24.5) This confirms the validity of the first hypothesis, which states that "There are statistically significant differences at the level of (0.05) between the average scores of the standard group students (the traditional teaching style) and the experimental group (with the teaching style using the proposed ES) in the cognitive aspects in favor of the experimental group".

This may be due to:

That the proposed system includes breakdowns display methods that outweigh exceeds the traditional presentation methods in terms of simplicity of presentation and the sequence of tracking causes or factors leading to disruptions.

This finding is consistent with the result study of $[5,8,12,13]$

Table 2 shows the value of $T$ test and average scores of the standard and experimental groups in the skill performance of the combined skills

\begin{tabular}{|l|l|l|l|l|l|}
\hline groups & $\begin{array}{l}\text { Number } \\
\text { of } \\
\text { students }\end{array}$ & average & $\begin{array}{l}\text { Standard } \\
\text { deviation }\end{array}$ & T & sig \\
\hline standard & 25 & 23.72 & 5.23 & \multirow{2}{*}{9.8} & \multirow{2}{*000}{} \\
\hline experimental & 28 & 33.60 & 0.9940 & & \\
\hline
\end{tabular}

Table (2) shows the following:

The mean level of significance is less than (0.05), which means rejecting the zero hypothesis and accepting the alternative hypothesis, meaning that there are statistically significant differences at $(0.05)$ between the standard group and the experimental group in the skill performance And for the experimental group, since the average score is (33.60), which is greater than the average score of the standard group (23.72), and the value of $T(9.8)$ This confirms the validity of the second hypothesis, which states that "There are 
statistically significant differences at the level of (0.05) between the average scores of the students of the standard group (with the traditional teaching style) and the experimental group (the teaching style using the proposed ES) in the skill performance and practical efficiency for the experimental group".

\section{This may be due to:}

That the proposed system included the display methods of breakdowns and processing steps outperformed traditional methods of presentation as they were supported by illustrations and the proposed system included a simple and attractive method of interaction between the student and the proposed system, and this result agrees with the study of [69].

\section{RESEARCH RESULTS}

- Analyzing the results of applying the proposed system to the students of ITE, the need of ITE to generalize the use of the proposed system.

- Interviews were held with different groups related to the current study problem, such as: technical education teachers, automotive specialists, car breakdown diagnosis specialists, car mechanics and automotive engineers, to form a conceptual vision of what should be added to the system, Information about common car breakdowns and handling steps.

- A proposed ES was designed to assist in the diagnosis and fixing of common car breakdowns and was applied to a sample of ITE students specializing in cars.

- $\quad$ There are statistically significant differences at the level of $(0.05)$ between the average scores of the students of the standard group (the traditional teaching style) and the experimental group (the teaching style using the proposed ES) in the skill performance and practical efficiency for the experimental group. The use of the proposed system and the need for ITE schools.

- There are statistically significant differences at the level of (0.05) between the average scores of the students of the standard group (the traditional teaching style) and the experimental group (teaching style using the proposed ES) in the cognitive aspects in favor of the experimental group. And the need for ITE schools.

- The study assured the importance of using the proposed system in ITE schools for its benefits.

- Some of the problems faced by students in the specialization of cars in ITE schools have been overcome.

\section{SEARCH RECOMMENDATIONS}

In the light of what was presented in the above, the research recommends the following:

- The importance of interest in ITE and work on its development.

- Benefiting from the proposed system and circulating it in industrial technical schools to assist students in the specialization of cars to diagnose and fix common car breakdowns.

- Awaring students and teachers of ITE about the benefits of using the proposed system.
- $\quad$ To change the society's inferior view of students and graduates of ITE.

- $\quad$ The need to design other models of the proposed system to serve different ITE specialties.

- $\quad$ The need to direct the efforts of researchers to serve and solve the problems of society and not be satisfied with theoretical studies.

- $\quad$ Utilize the proposed ES in the field of diagnosing and fixing common breakdowns in other sectors serving the community.

\section{CONCLUSION AND FUTURE WORK}

Of all the above, it is clear that the ITE schools are in bad need of the proposed system for its benefits.

As for future scope we will try to develop this proposed system to help in fixing all car breakdowns, not only the common ones.

\section{ACKNOWLEDGMENTS}

The researchers extend their sincere thanks and appreciation to all those who assisted them in the various stages of research from experts and specialists in the field of car repair and maintenance, automotive mechanics engineers, industrial technical education teachers, Managers of schools that have their search experience.

\section{REFERENCES}

[1] World Health Organization, Road traffic injuries. 2017.

[2] Central Agency for Public Mobilization and Statistics, Road accidents. 2017.

[3] Mohammed, O. Learn the workmanship ".. Conference for the development of technical education at Assiut University". 2017 [cited 2018 23/3/2018]; Available from:

http://www.masrawy.com/News/News_Regions/details/2 017/2/23/1033320/-

\%D8\%A7\%D8\%AA\%D8\%B9\%D9\%84\%D9\%85-

$\% \mathrm{D} 8 \% \mathrm{~B} 5 \% \mathrm{D} 9 \% 86 \% \mathrm{D} 8 \% \mathrm{~B} 9 \% \mathrm{D} 8 \% \mathrm{~A} 9$

\%D9\%85\%D8\%A4\%D8\%AA\%D9\%85\%D8\%B1\%D9\%84\%D8\%AA\%D8\%B7\%D9\%88\%D9\%8A\%D8

$\% \mathrm{~B} 1-$

$\% \mathrm{D} 8 \% \mathrm{~A} 7 \% \mathrm{D} 9 \% 84 \% \mathrm{D} 8 \% \mathrm{AA} \% \mathrm{D} 8 \% \mathrm{~B} 9 \% \mathrm{D} 9 \% 84 \% \mathrm{D} 9$

$\% 8 \mathrm{~A} \% \mathrm{D} 9 \% 85$

\%D8\%A7\%D9\%84\%D9\%81\%D9\%86\%D9\%8A-

$\% \mathrm{D} 8 \% \mathrm{~A} 8 \% \mathrm{D} 8 \% \mathrm{AC} \% \mathrm{D} 8 \% \mathrm{~A} 7 \% \mathrm{D} 9 \% 85 \% \mathrm{D} 8 \% \mathrm{~B} 9 \% \mathrm{D} 8$

\%A9-\%D8\%A3\%D8\%B3\%D9\%8A\%D9\%88\%D8\%B7

[4] Belkasi, M., Artificial intelligence. 2016.

[5] AlSharawy, A.s.M., Suggested Form For Using Expert Systems In Pre-University Education, in Computer Teacher Preparation Department. 2009, damietta: faculty of speciefic education.

[6] Jindal, Y., Approach towards car Failure Diagnosis-An Expert System. international journal of Computer Applications, 2010. 1.

[7] Saeed, S.M., Design of Intelligent Database System for Vehicle Fault Diagnosis. 2011, Middle East University Jordan: Faculty of information technology.

[8] Saidi, M.A.-S.A.A.-. The impact of instructional design expert system in developing the skills of producing electronic courses among graduate students at the faculty 
of education, in Arab Studies in Education and Psychology (ASEP). 2015. p. 205-239.

[9] OLANLOYE, D.O., AN EXPERT SYSTEMS FOR DIAGNOSING TRACTOR FAILURE AND MALFUNCTION. IJASCSE, 2013. 2(6).

[10] Jarida, S.E.M.D.M.A.-. Proposed strategy for industrial technical education in Egypt to meet the needs of the labor market. ASEP, 2014.

[11] Nasr, S., Traffic accidents in Egyptian society. 2010, National Center for Social and Criminal Research: National Library and Archives.

[12] Mohammed, A.S.A.K., The Effectiveness of a program for developing the skills of cars maintenance course for the industrial secondary schools students in the light of the technological innovations, in Department of Curriculum and Teaching Methods. 2011, Helwan University: Faculty of Education.

[13] Ahmed, A.A.N., Industrial Secondary Education Outputs and Labor Market Needs in Egypt, in Faculty of Administration and Economics. 2014, Arab Academy in Denmark.
[14] SDEEK, R.S., A MOBILE EXPERT SYSTEM APPLICATION FOR SOLVING PERSONAL COMPUTER PROBLEMS. Journal of Technical-Online, 2016. 15.

[15] Hassan, A.S., Logic and artificial intelligence. 2011.

[16] Al-Faki, A.I., Artificial intelligence and expert systems. 2012, Dar Al Thaqafa for Publishing and Distribution.

[17] Ibrahim, M.I.S., Effectiveness of a program based on expert systems to develop logical thinking among high school students, in Department of Education Technology. 2012, Helwan University: Faculty of Education.

[18] BRAINS, J. IntelliJ IDEA. 2018 [cited 2018 28-3-2018]; Available from: http://www.jetbrains.com/idea/features/.

[19]sourceforge. JavaScript for Artificial Intelligence. 2018 [cited 2018 28-3-2018]; Available from: http://mind.sourceforge.net/js.html.

[20]Green, S.S.B., AngularJS: Up And Running. 2014, United States of America: O'Reilly Media, Inc. 275.

[21] js, n. node js. 2018 [cited 2018 27-3-2018]; Available from: https://nodejs.org/en/ 